\title{
AUTISMO E APRENDIZAGEM: ENTENDER PARA INTERVIR
}

\author{
IRADI ALVES SOARES DE SOUSA ${ }^{1}$ \\ LARISSE DE ARAUJO SAMINEZ ${ }^{2}$ \\ JOANA MARIA MORAES AGUIAR ${ }^{3}$
}

\section{RESUMO}

Essa pesquisa visa refletir acerca da importância de compreender o TEA-Transtorno de Espectro Autista, bem como, suas possíveis causas e implicações na vida escolar social das crianças de modo a intervir de forma satisfatória no acompanhamento através da abordagem pedagógica. O Transtorno do Espectro Autista é um distúrbio complexo multifatorial e geneticamente heterogêneo. Deste modo compreender o autismo e suas implicações na aprendizagem torna-se essencial uma vez que, auxilia na tomada de decisão e na própria abordagem pedagógica de modo a promover a aprendizagem de forma significativa possibilitando as crianças com autismos superar as suas dificuldades e quebrar barreira que as impeçam de obter sucesso escolar.

Palavras-chave: Autismo. Aprendizagem. Intervenção

ABSTRACT: his research aims to reflect on the importance of understanding ASD as well as its possible causes and implications in children's social school life in order to intervene satisfactorily in the monitoring through the pedagogical approach. Autism Spectrum Disorder is a multifactorial and genetically heterogeneous complex disorder. Thus, understanding autism and its implications for learning becomes essential since; It assists in decision making and in the pedagogical approach itself in order to promote learning significantly, enabling children with autism to overcome their difficulties and break down barriers that prevent them from achieving school success.

Keywords: Autism. Learning. Intervention

1 Pedagoga, licenciada em matemática e pós-graduanda em educação especial

2 Licenciada em Pedagogia e pós-graduanda em educação especial

3 Pedagoga, e pós-graduanda em educação especial 


\section{INTRODUÇÃO}

Sabe-se que a aprendizagem escolar é um fator que envolve muitos condicionantes e que depende de uma série de condições para que ela aconteça de forma plena e satisfatória, como por exemplo os fatores ambientais, genéticos e sociais e até pedagógicos

Contudo sabemos que pode haver alguns percalços nesse processo que pode dificultar o aprendizado, sabe- se ainda que cada ser humano é único e aprende em um ritmo diferente, uns aprendem, mais rápido outro mais lentamente. Nem todas as crianças aprendem da mesma forma ou apresentam as mesmas facilidades para aprender, algumas podem apresentar extremas dificuldades.

É o caso das crianças que apresentam autismo, que demandam uma atenção especial e requerem uma metodologia e práticas diferenciadas devido as suas especificidades.

O transtorno do espectro autista é distúrbio complexo multifatorial e geneticamente heterogêneo, que afeta a interação social, mas que também pode se apresentar de várias formas.

Deste modo compreender o autismo e suas condições torna-se essencial uma vez que irá auxiliar na tomada de decisão e na própria intervenção pedagógica de forma a promover a aprendizagem de forma significativa possibilitando as crianças com autismos superar as suas dificuldades e quebrar barreira que o impeçam de obter sucesso escolar.

O tema se justifica pela importância social e educacional uma vez que, contribui para a formação e conhecimento dessa temática ainda pouco discutida no meio escolar, o que corrobora para o desconhecimento do assunto nas instituições de ensino.

Também visa refletir acerca da importância de compreender o espectro autista bem, como suas possíveis causas e implicações na vida escolar social e emocional das crianças de modo a intervir de forma significativa através da abordagem pedagógica.

Desta forma, o presente trabalho espera contribuir para a formação dos profissionais da área da educação que direta ou indiretamente trabalham com crianças autistas tendo em vista melhorar a sua pratica pedagógica em sala de aula e auxiliar na rotina dessas crianças que pode ser muito dura e cruel se não trabalhada 
de forma correta e com as ferramentas necessárias para o seu desenvolvimento, minimizado as barreiras que os impedem de lograr êxito na sua caminhada escolar.

Essa pesquisa é de caráter qualitativo e objetiva, realizada através de pesquisas bibliográficas com a finalidade de analisar as propostas de alguns teóricos que discorrem sobre o tema afim de possibilitar melhor familiaridade com o mesmo e provocar a construção de novas hipóteses.

Esse trabalho visa contribuir para aqueles que se interessam por essa temática possibilitando uma maior explanação sobre o assunto permitindo também a delimitação da temática e de seus objetivos, tornando o problema mais explícito.

Em suma espera-se que o mesmo possa contribuir para a nossa formação e proporcionar novos conhecimentos, que permitam reflexões e aprofundamentos mais significativos sobre este assunto de extrema relevância educacional e social.

O presente estudo tem como objeto de pesquisa o TEA - transtorno do espectro autista e almeja compreender essa temática dentro do contexto escolar, conhecer suas possíveis causas e consequência, bem como suas características e implicações nas vidas das pessoas com autismo. Ao mesmo tempo que se questiona como o autismo se apresenta, quais as estratégias podem ser usadas para intervi na rotina da criança com autismo.

Essas questões pertinentes e que serão respondidos ao longo deste trabalho ao analisar artigos e concepções teóricas que irão auxiliar nesta pesquisa. O presente artigo foi estruturado em três seções. Na primeira, serão abordadas a origem e concepção histórica do autismo. Em seguida, será destacada as várias definições sobre o espectro do autismo bem como suas possíveis causas e consequências e por fim serão apresentadas algumas estratégias e abordagens pedagógicas sobre como intervi em sala de aula no trabalho com crianças autistas. Dentre os teóricos utilizados para a realização dessa pesquisa estão: Silva (2012), Mantagute (2008) dentre outros.

\section{CONTEXTO HISTORICO DO AUSTISMO}

Nos primórdios da psiquiatria, na virada do século XVIII para o XIX, o diagnóstico de "idiotia" cobria todo o campo da psicopatologia de crianças e adolescentes. Logo, a idiotia pode ser considerada precursora não só do atual retardo mental, mas das psicoses infantis, da esquizofrenia infantil e do Transtorno do Espectro do Autismo (BERCHERIE,1998) 
No entanto Eugene Bleuler em 1911 foi quem introduziu o termo autismo ao se referir aquelas crianças que pareciam não manter um contato com a realidade, produzindo um déficit na comunicação, este fora criado para descrever sintomas de esquizofrenia como sendo uma fuga da realidade sintomas esses observados em seus pacientes. (KANNER, 1997). Contudo, Leo karner em, 1943, foi o primeiro medico a falar sobre crianças que pareciam viver em 'mundinhos' pois não interagiam com os outros. Ele também foi quem pela primeira vez usou o termo 'mães geladeiras' para designar aquelas mães que eram frias com os seus filhos, pois para ele esse fator estava associado ao autismo. No mesmo ano o austríaco Hans Asperge descreveu em sua tese de doutorado a psicopatia da infância. Em 1952 o DSM II trouxe pela primeira vez o termo autismo.

Mas este estaria associada a sintomas de esquizofrenia. A parti de $1980 \mathrm{com}$ o DSM III houve a separação entre esquizofrenia e autismo, pois não havia qualquer relação entre elas. Posteriormente o DSM IV trouxe uma nova definição para autismo já especificando a tríade dificuldade de comunicação, interação e interesses restritos, contudo ainda havia muitos especificações e possiblidades de classificação para o autismo como a síndrome de Rett, Síndrome de Asperge (SILVA, 2012).

A partir de 2013 com a nova versão do DSM V o autismo passa a ter uma nova denominação, TEA - transtorno do espectro autista passando a integrar todas as classificações essa única denominação.

\subsection{AUTISMO: ALGUMAS DEFINIÇÕES}

Atualmente o autismo é concebido como uma síndrome de múltiplas causas, onde estariam inter-relacionados ao biológico, a genética e orgânica durante o processo de construção do ser. Como dito anteriormente o autismo é uma síndrome multifatorial, o que dificultou por muito tempo a sua definição, existindo assim várias definições para este. Para a AMA - (associação americana de autismo) o autismo é entendido como:

O autismo é uma deficiência do desenvolvimento complexa que tipicamente aparece durante os 3 primeiros anos de vida e afeta a capacidade do indivíduo de se comunicar e interagir com os outros, apresenta um conjunto de comportamentos que afeta de formas e graus diferentes para cada indivíduo, não há uma causa única conhecida para autismo. Mas em sua, maioria é plausível a causa ser vinculada a anormalidades na estrutura dos cérebros ou função cerebral. 
O DSM-V (2013) afirma que o TEA 'caracteriza-se por um transtorno do neurodesenvolvimento com prejuízos persistente na comunicação recíproca social e interação social e de acesso restrito a padrões de comportamentos repetitivos, interesses ou a determinadas atividades. Para Schmidt, 2013, p. 13), "[...] o TEA é definido como um distúrbio do desenvolvimento neurológico que deve estar presente desde a infância, apresentando déficit nas dimensões sócio comunicativa e comportamental".

Conforme as CID-10- o autismo infantil, transtorno global do desenvolvimento caracterizado por desenvolvimento anormal ou alterado, manifestado antes da idade de 3 anos, apresentando uma perturbação característica no funcionamento em cada um dos três domínios seguintes:

$\checkmark \quad$ Interação social - a pessoa com autismo tende a ter extrema dificuldade em estabelecer uma regra de comportamento social, como conservar amizades, manter um diálogo, manter contato visual; dificuldades em compreender certas situações e coloca-se no lugar dos outros, o que pode impedir o estabelecimento das relações interpessoais. A criança pode evitar contato visual, recusar contato físico, praticamente não demonstrar iniciativa para se aproximar de outras pessoas e compartilhar com elas os seus interesses, manter-se isolada em situações sociais, não atender quando chamada pelo nome. Não é incomum que a criança apresente vínculo específico e exagerado com uma pessoa.

$\checkmark \quad$ Comunicação - pessoas com autismo também podem apresentar prejuízos na comunicação, comportamentos estereotipados, movimentos repetitivos como gestos com as mãos; muitas vezes podem parecer inconsequentes e até taxadas de mal-educadas, isso por conta da dificuldade que elas têm em compreender determinadas situações em um diálogo. A pessoa com autismo é incapaz de entender por exemplo uma metáfora, piada, trocadilhos.

$\checkmark$ Comportamento focalizado ou repetitivo - outra característica bem peculiar das pessoas com autismo é o hiperfoco; pessoas com autismo podem ter fascinação por determinado assunto ou objeto chegando a ser quase um exper. Nisso. geralmente assuntos que envolvem carros, dinossauros, aviões entre outros.

Essas características podem variar de acordo com o grau ou nível em que o autismo se apresenta que também podem vim associados ou combinados com outros transtornos ou problemas de aprendizagem. As chamadas comorbidades no autismo. 
[...] pode-se compreender que "o uso atual da nomenclatura Transtorno do Espectro Autista possibilita a abrangência de distintos níveis do transtorno, classificando-os de leve, moderado e severo". Assim, não se pode homogeneizar o sujeito com autismo, considerando que são sujeitos diversos, com níveis de intelectualidade diferentes. É viável o conhecimento mais sucinto das características desse Transtorno. (CUNHA, 2015, p. 23).

- Leve - no grau leve; também antes conhecido como Asperger é um autismo tipicamente leve, por esta razão, pode muitas vezes passar despercebido e difícil de diagnosticar pois a pessoa pode apresentar poucas características. No autismo leve não necessariamente há atraso na linguagem, mas a pessoa com autismo pode ignorar um diálogo ou interação social. Pode apresentar variação de QI, podendo ser mais ou menos inteligentes, mas sem apresentar comprometimento intelectual como DI, crianças com autismo leve podem ser extremamente inteligentes; alguns até superdotados.

- Moderado - no grau 2 a pessoa a pode apresentar um maior comprometimento na linguagem verbal; na área motora, QI abaixo da média, comportamentos repetitivos. Estereotipias motoras, apego as rotinas necessitando assim de um maior apoio para aprender e executar atividades simples diária e da vida pratica, tem dificuldades de estabelecer relações sociais. Podendo ser também bastantes agressivas.

- $\quad$ Severo - possuem severos prejuízos na comunicação verbal; estereotipias motoras. Resistências a mudança de rotinas. Comportamentos restritos ou repetitivos; onde pode estar associado a DI e ao TDAH. Nesse nível é importante acompanhamento e terapia pois a pessoa pode ser extremamente dependente inclusive para atividades práticas da vida daria, como cuidados básicos de higiene por exemplo tomar banho; escovar os dentes, vesti- se pentear os cabelos, amarrar os sapatos.

Segundo a Organização das Nações Unidas (ONU), cerca de 70 milhões de pessoas no mundo são acometidas pelo transtorno, sendo que, em crianças, é mais comum que o câncer, a Aids e o diabetes. Por esta razão o autismo tem sido cada vez mais discutidos nos meios acadêmicos embora ainda sejam desconhecidas muitas das suas causas e genes. No brasil ainda não temos dados oficias sobre autismo.

\subsection{POSSIVEIS CAUSAS E CONSEQUENCIAS DO AUTISMO}


Até os dias atuais não se encontra uma causa específica sobre a questão, mas sabe-se que embora desconhecida, existe um consenso entre os pesquisadores da existência de um componente genético na origem do autismo, além da influência ambiental.

Há ainda muito o que se discutir acerca das causas do autismo. Pois hoje sabe-se que não é gerado por uma única causa identificada, mas que podem ser variadas e responder a diversas razoes, considerando um transtorno comportamental onde evidencias apontam para a sua multicausualidade.

Desta maneira não existe uma causa básica fundamental para todos os casos de autismo, porem estudos demostram indiscutivelmente que os fatores biológicos/genéticas, neurobiológicos; psicológicos estão implicados na origem do autismo.

2.2.1 Fatores genéticos- diversas pesquisas têm revelado cada vez mais a relação entre os fatores genéticos/ biológicas e o autismo, hoje sabe-se que o autismo é marjoritavelmente genético e a herdabilidade no autismo também é considerável. Nos últimos anos várias pesquisas têm sido desenvolvidas no intuito de fazer novas descobertas a cerca genética humana entre elas o projeto genoma humano que busca estudar e mapear os genes do corpo humano afim de identificar, conhecer e entender os genes que estão relacionados a doenças raras como síndromes inclusive sobre o autismo.

Porem devido as especificidades dessa síndrome, não se sabe ao certo quais os genes estão relacionados a ele pois nem todos os genes ligados ao autismo foram identificados. O que se sabe é que a prevalência do autismo em crianças de uma família que já tenha uma criança autista é bem maior do que em uma família que não tenha histórico de autismo chegando até 2- 3\% a mais de nascer outra criança autista, além disso. Estudos genéticos indicam que essa prevalência do autismo numa mesma família é bem maior chegando a 200 vezes a mais se comparado a população normal

2.2.2 Neurobiológicos - como dito anteriormente ao nascer a criança carrega consigo um projeto de desenvolvimento que e determinado pela herança genética mas a medida que a criança vai construindo a sua experiência sensorial e visceral com a mãe suas primeiras relações objetais permitirão completar gradualmente sua estruturação neurológica e psíquica qualquer alteração ou desorganização neste processo poderá resultar em uma anormalidade neurológica. Sendo essas uma das possíveis explicações para o autismo e outros transtornos do neurodesenvolvimento. 
2.2.3 ambientais Fatores ambientais podem desempenhar um papel mais importante do que se pensava no desenvolvimento do autismo, pesquisas sugerem que algo no contexto do nascimento - remédios, químicas ou infecções - podem desencadear o autismo em crianças que já têm predisposição genética para desenvolver a doença.

\subsection{CARACTERISTICAS DAS PESSSOAS COM AUTISMO}

Como dito anteriormente as características do autismo podem variar de acordo com o nível de comprometimento, no entanto crianças com autismo também podem ser extremamente inteligentes elas podem apresentar a mais diversas características pois o autismo em cada pessoa pode ser único. Há pessoas por exemplo que podem não ter comprometido há fala outros sequer falarão há autistas que podem ser extremamente dóceis e sociáveis outros já não; se tratando de autismo cada caso é um caso. Mas no geral apresentam as seguintes características:

$\checkmark \quad$ Não adquirem a fala ou muito raramente a usam;

$\checkmark \quad$ Dificuldades em generalizar conceitos;

$\checkmark$ Ecolalia;

$\checkmark \quad$ Necessidade de uniformidade e rotina;

$\checkmark \quad$ Interesses restritos e limitados;

$\checkmark \quad$ Comportamentos repetitivos.

\section{ESTRATÉGIAS DE INTERVENCAO PEDAGOGICA}

Mediante o que já foi mencionado sobre autismo fica a dúvida, como trabalhar com essas crianças? Essa é uma dúvida frequente em que muitos pais e professores se perguntam o que podem fazer para auxiliar essas crianças no dia- a -dia escolar.

Nesse sentido é importante direcionamos nossos olhares, também para 0 âmbito escolar, onde a criança deve ser acolhida de forma inclusiva, atentando sempre as suas potencialidades e não as suas dificuldades criando alternativas para a ação educativa de alunos com autismo. 
Para isto o primeiro passo é uma adaptação curricular que seja funcional e permita que seja estimulado a sua autonomia e aprendizado. É essa visão que amplia as ações, tornando-a aprendizagem mais significativas e prazerosas.

Embora haja uma variedade de estratégias de intervenção destinados a alunos com autismo e usados em muitos ambientes educacionais, não é possível dizer que haja uma comprovadamente eficaz pois em cada indivíduo com autismo pode apresentar características diferentes, logo necessidades diferentes, respeitar as singularidades e as diferentes formas de aprender de cada um é de extrema importância, possibilitar deferentes vivências e situações de aprendizagem.

A utilização de materiais pedagógicos é muito importante na intervenção com o autista porque permite atividades de exploração sensorial, são objetos muito simples, mas que estimulam o raciocínio e são muito utilizados tanto com alunos com autismo quanto com crianças sem autismo.

3.1 Figuras - A utilização de figuras pode ser um fortalecedor na comunicação para os autistas que não desenvolvem a linguagem, poucos autistas têm uma fala funcional este recurso seria um facilitador permitindo que o autista se expresse para isto é preciso que o autista possua um nível de compreensão mínimo, não tenha comprometimento visual e tenha coordenação motora mínima.

Este tipo de comunicação por troca de figuras tem que ser significativo para o autista e por ser comportamental estimula a criança a pedir o que deseja através da figura correspondente ao seu desejo de expressar, além de estimular o pensamento simbólico. É um sistema de comunicação muito útil caso a família deseje adotar em parceria com a escola, não exigindo que sejam especialistas para utilizar este sistema, é importante que os problemas de comunicação primeiramente sejam resolvidos para que posteriormente se possa orientar a prática pedagógica.

3.2 Jogos - os jogos pedagógicos são umas das ferramentas muito útil quando usado de forma correta e pode auxiliar muito na aprendizagem escolar da criança com autismo e é um excelente recurso para o educador porque permite que seja desenvolvida uma atividade a partir do concreto e que seja possível a exploração de texturas, formas, encaixes, tamanho, possibilitando que o educador perceba os esquemas mentais formados pelo aluno e promova o desenvolvimento cognitivo; conforme explicita (RODRÍGUEZ, 2012) 
motrizes, cognitivas. Assim mesmo, o jogo oferece a possibilidade de assumir um papel ativo frente à realidade e à aprendizagem dentro e fora da escola. (RODRÍGUEZ, 2012 p.12).

\subsection{Rotina}

A rotina, segundo Mantagute (2008), pode ser definida como uma categoria pedagógica utilizada nas instituições educativas para auxiliar o trabalho do educador, sobretudo, para garantir um atendimento de qualidade para as crianças. Para a autora a rotina também;

Pode ser considerada uma forma de assegurar a tranquilidade do ambiente, uma vez que a repetição das ações cotidianas sinaliza às crianças cada situação do dia. Ou seja, a repetição de determinadas práticas dá estabilidade e segurança aos sujeitos. Saber que depois de determinada tarefa ocorrerá outra, diminui a ansiedade das pessoas, sejam elas grandes ou pequenas (MANTAGUTE, 2008).

O trabalho com a rotina ajuda a criança não só com autismo a se orientar e reorientar no espaço e até mesmo o professor em suas atividades, possibilitando uma maior organização de suas práticas.

O enfoque teórico e o fazer pedagógico são essenciais para a compreensão do trabalho para com a criança com Transtorno do Espectro do Autismo, conduzindo, assim a não apenas o reconhecimento do transtorno, mas a um direcionamento para além dos muros da escola.

\section{CONSIDERAÇÕES FINAIS}

Mediante o que foi mencionado com base nas observações apresentados aqui, percebe-se que o tema autismo é algo que tem ganhado cada vez mais espaços nos debates e discursões no meio acadêmico, isso deve-se a sua relevância no meio educacional, o que tem contribuído para o conhecimento desta temática.

Como discutido a aprendizagem é algo consideravelmente importante na vida do indivíduo pois é ela quem irá proporcionar o caminho para novas descobertas. Desta forma entende-se, o quanto é importante estimular as crianças com autismo a superaram suas dificuldades e conhecer suas potencialidades descobrindo assim a maneira de melhor ensiná-los, no sentido de trabalhar as estratégias corretamente com a crianças possibilitando a sua aprendizagem 
O fato é que esta temática não se esgota com este trabalho e que ainda há muito a se descobrir sobre o autismo, contudo, esperamos que as ideias aqui apresentadas, possam ser adicionadas a tantas outras já existentes, e que possam contribuir para mais pessoas que se interessam sobre o tema.

Com esta pesquisa, espera-se contribuir para que pais, professores esclareçam algumas dúvidas e compreendam os inúmeros desafios que uma criança com autismo tem que superar. Para isto o primeiro passo é reconhecer está problemática, conhecer as suas especificidades e a importância de trabalhar as estratégias pedagógicas corretamente.

O enfoque teórico e o fazer pedagógico são essenciais para a compreensão do trabalho para com a criança com Transtorno do Espectro do Autismo, conduzindo, assim a não apenas o reconhecimento do transtorno, mas a um direcionamento para além dos muros da escola.

Para isso, entende-se que, a intervenção pedagógica, envolvendo-se de forma responsável, todos aqueles que direta ou indiretamente fazem parte desse processo. A escola, a família, a comunidade escolar, são os suportes para a concretização desse direito que jamais deve ser negado ou negligenciado.

O presente trabalho tratou de uma pesquisa de caráter qualitativo feita através de pesquisa bibliográfica, a fim de permitir novas possibilidades, que impulsionaram reflexões e aprofundamentos sobre o tema abordado, onde foram analisadas as propostas de alguns teóricos que discorrem sobre o tema afim de possibilitar melhor familiaridade com o mesmo e provocar a construção de novas hipóteses.

Os dados analisados foram revisados de diversos endereços elet como consta nas referências abaixo. Além disso, foram utilizados document são considerados marcos legais que deram embasamento as estas pesquisas.

\section{REFERÊNCIAS}

BERCHERIE, paul. a clínica da psiquiatria de criança: estudo histórico. malentendido. 3, 1998.

CUNHA, Eugenio. Autismo e inclusão: psicopedagogia práticas educativas na escola e na família. 6 ed. Rio de Janeiro: Wak Ed. 2015. 140 p. 
DSM-V.American Psychiatric Association. (2013). Manual Diagnóstico e Estatístico de Transtornos Mentais (DSM - V). Porto Alegre: Artes Médicas.

KANNER, L. "Os Distúrbios Autísticos do Contato Afetivo." In: ROCHA, P. S. (org.) Autismos, São Paulo: Editora Escuta, 1997.

MANTAGUTE, ELISÂNGELA L.L (2008). Rotinas na Educação Infantil. Disponível em:

ttp://200.195.151.86/sites/educacao/images/stories/elisangelarotinas_na_educacao_i nfantil.pdf. Acesso em 11 de agosto de 2019.

OMS (ORGANIZAÇÃO MUNDIAL DA SAÚDE) "Classificação de Transtornos Mentais e do Comportamento da CID" - 10: Descrições Clínicas e Diretrizes Diagnósticas, Porto Alegre: Artes Médicas, 1993.

RODRÍGUEZ, C. H. (2012) Influencia e importância del juego em el desarrollo de niños con autismo de 0 a 6 ãnos. Instituto Superior de Estudios Psicologicos. Disponível em: https://www.isep.es/wp-content/uploads/2014/07/influencia-eimportancia-del-juego-en-eldesarrollo-de-ninos-con-autismo-de-0-a-6-anos.pdf.

Acesso em 20 setembro de 2019

SCHMIDT, Carlo. Autismo, educação e transdisciplinaridade. In: SCHMIDT, C (org.) Autismo, educação e transdisciplinaridade. Campinas, SP: Papirus, 2013.

SILVA, Ana Beatriz Barbosa; GAIATO, Mayra Bonifácio; REVELES, Leandro Tadeu. Mundo singular: entenda o autismo. Fontana, 2012. Disponível em: <http://cursoposneuro.com.br/wpcontent/uploads/2015/08/MundoSingularEntenda-o Autismo.pdf>. Acesso em 20 de jul. de 2019. 
IRADI ALVES SOARES DE SOUSA

LARISSE DE ARAUJO SAMINEZ

JOANA MARIA MORAES AGUIAR

\section{AUTISMO E APRENDIZAGEM: ENTENDER PARA INTERVIR}

Trabalho de conclusão de curso à Faculdade de Filosofia Ciências e Letras de Boa Esperança (FAFIBE) com o objetivo do titulo de especialista em Educação Especial.

Aprovado em

Nota:

BANCA EXAMINADORA

Gisele Maria Araujo (Orientadora)

Mestra em Educação/UFMA

Prof. Nome do Professor Avaliador

Vargem Grande - Ma

2019 